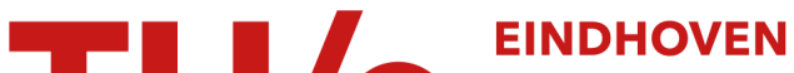 \\ UNIVERSITY OF \\ TECHNOLOGY
}

\section{Interactive effects in the reactive ion etching of SiGe alloys}

\section{Citation for published version (APA):}

Oehrlein, G. S., Zhang, Y., Kroesen, G. M. W., Frésart, de, E., \& Bestwick, T. D. (1991). Interactive effects in the reactive ion etching of SiGe alloys. Applied Physics Letters, 58(20), 2252-2254. https://doi.org/10.1063/1.104942

DOI:

10.1063/1.104942

Document status and date:

Published: 01/01/1991

\section{Document Version:}

Publisher's PDF, also known as Version of Record (includes final page, issue and volume numbers)

\section{Please check the document version of this publication:}

- A submitted manuscript is the version of the article upon submission and before peer-review. There can be important differences between the submitted version and the official published version of record. People interested in the research are advised to contact the author for the final version of the publication, or visit the $\mathrm{DOI}$ to the publisher's website.

- The final author version and the galley proof are versions of the publication after peer review.

- The final published version features the final layout of the paper including the volume, issue and page numbers.

Link to publication

\section{General rights}

Copyright and moral rights for the publications made accessible in the public portal are retained by the authors and/or other copyright owners and it is a condition of accessing publications that users recognise and abide by the legal requirements associated with these rights.

- Users may download and print one copy of any publication from the public portal for the purpose of private study or research.

- You may not further distribute the material or use it for any profit-making activity or commercial gain

- You may freely distribute the URL identifying the publication in the public portal.

If the publication is distributed under the terms of Article 25fa of the Dutch Copyright Act, indicated by the "Taverne" license above, please follow below link for the End User Agreement:

www.tue.nl/taverne

Take down policy

If you believe that this document breaches copyright please contact us at:

openaccess@tue.nl

providing details and we will investigate your claim. 


\title{
Interactive effects in the reactive ion etching of SiGe alloys
}

\author{
G. S. Oehrlein, Y. Zhang, G. M. W. Kroesen, E. de Fresart, and T. D. Bestwick \\ IBM Research Division, T. J. Watson Research Center, Yorktown Heights, New York 10598
}

(Received 17.December 1990; accepted for publication 18 February 1991)

\begin{abstract}
Reactive ion etching (RIE) of epitaxial, strained $\mathrm{Si}_{1-x} \mathrm{Ge}_{x}$ alloys, $x<0.20$, in fluorine-, ehlorine-, and bromine-based low-pressure plasmas has been investigated. The SiGe etch rates increase for each etchant with Ge concentration, e.g., for fiuorine-based RIE ( $\mathrm{CF}_{4}$ and $\mathrm{SF}_{6}$ ) the etch rate of a $\mathrm{Si}_{80} \mathrm{Ge}_{20}$ alloy is $\simeq 2 x$ that of elemental $\mathrm{Si}$. Analysis shows that the etch rate increase is not accounted for by the greater rate of gasification of Ge atoms alone but that the presence of Ge atoms in the SiGe alloy increases the rate of Si etch product formation.
\end{abstract}

Currently there is a great deal of interest in the study of the material properties and the processing characteristics of epitaxial silicon-germanium alloys grown on silicon. This interest is based on the ability to tailor the band gap and electronic properties of the SiGie alloy according to the requirements of a variety of novel electronic devices ${ }^{1,2}$ and has been fueled by progress in thin-film growth techniques. ${ }^{1,3-5}$ Dry etching of SiGe alloys will be required in the fabrication of these new devices and circuits and at this time little is known about how it differs from the dry etching behavior of $\mathrm{Si}$ and $\mathrm{Ge}^{6}$. The investigation of halogen-based plasma etching of epitaxial $\mathrm{Si}_{1}{ }_{x} \mathrm{Ge}_{x}$ on $\mathrm{Si}$ is also interesting from a scientific point of view since it can be viewed as a model system for the study of the interaction of a multicomponent substrate with an etching plasma, having the attraction of flexible composition without change in crystal structure and the availability of a great deal of data on the variation of strain, band gap, etc. with alloy composition.

In this letter we report on the reactive ion etching (RIE) of epitaxial, strained $\mathrm{SiGe}$ thin films on $\mathrm{Si}(100)$ with a $G e$ content of up to $220 \%$ in $\mathrm{CF}_{4}, \mathrm{SF}_{6}, \mathrm{CF}_{2} \mathrm{Cl}_{2}$, and $\mathrm{HBr}$. For $\mathrm{CF}_{4}$ and $\mathrm{SF}_{6}$ plasmas atomic fiuorine is the primary etching species, ${ }^{7}$ for $\mathrm{CF}_{2} \mathrm{Cl}_{2}$ plasmas etchng is due to atomic $\mathrm{Cl}$ (Refs. 8 and 9) and in the case of $\mathrm{HBr}$ discharges etching is due to attack of $\mathrm{Br}$ atorns. ${ }^{10,11}$ Undoped SiGe-alloy films with a film thickness of up to $800 \mathrm{~nm}$ were grown on $5 \mathrm{in.} \mathrm{Si(100)} \mathrm{substrates} \mathrm{using} \mathrm{ultrahigh} \mathrm{vacuum/}$ chemical vapor deposition (UHV/CVD) ${ }^{4,12}$ Sample chips measuring $1.5 \times 1.5 \mathrm{~cm}^{2}$ were cut from the wafers and reactive ion etched in a $13.56 \mathrm{MHIz}$ reactor which has been described previously. ${ }^{13,14}$ During RIE the samples were placed in the center of a $30-\mathrm{cm}$-diam electrode made of $\mathrm{Cu}$ and $\mathrm{Al}$, which was water cooled $\left(15^{\circ} \mathrm{C}\right)$ and covered for the present experiments with a 2 -mm-thick quartz plate. For RIE $200 \mathrm{~W}$ rf power was applied to the electrode using an automatic matching network. A flow rate of $100 \mathrm{sccm}$ was used for all gases, and a pressure of $25 \mathrm{mTorr}$ was chosen. Etch rates of the SiGe alloys were determined in situ using ellipsometry at $632.8 \mathrm{~nm}$. Oxide and photoresist patterned samples were also etched to determine etch profiles. The surface chemistry of the SiGe alloys after $5 \mathrm{~min}$ of reactive ion etching, i.e., after steady-state etching conditions had been established, was studied using $\mathrm{X}$-ray photoemission employing $\mathrm{Al} K \alpha$ excitation. For these mea- surements the samples were moved under vacuum into a UHV surface analysis system (pressure $=10^{-10}$ Torr). The time between the end of the RIE process and acquisition of XPS data was lesss than 10 min. For the present work photoelectron spectra were acquired at grazing electron emission $\left(15^{\circ}\right.$ from the surface).

In Fig. 1 etch rates of SiGe alloys are shown as a function of Ge content in $\mathrm{CF}_{4}, \mathrm{CF}_{2} \mathrm{Cl}_{2}$, and $\mathrm{HBr}$ plasmas. For comparison the etch rates of single-crystal $\mathrm{Si}$ and $\mathrm{Ge}^{-}$ are shown. The etch rates of the SiGe alloys increase with the Ge content for each etching gas which is qualitatively consistent with the greater etch rate of Ge as compared to Si. The dashed lines which connect the SiGe alloy data with the elemental Ge etch rate data are intended to help in the comparison of SiGe and Ge etch rates, but it is not implied that the actual etch rates would show a dependence on Ge content given by the dashed lines. The SiGe etch rate shows the strongest increase with Ge content for the $\mathrm{CF}_{4}$ plasma.

Analysis of profiles etched in photoresist- or oxidemasked SiGe films has shown that mask undercutting takes place for fluorine-rich discharges, e.g., $\mathrm{SF}_{6}$. No mask undercutting was observed with $\mathrm{CF}_{2} \mathrm{Cl}_{2}$ and $\mathrm{HBr}$ plasmas. These etch profile characteristics indicate that for $\mathrm{Si}_{1}-{ }_{x} \mathrm{Ge}_{x}$ alloys $\mathrm{F}$-based etching is ion assisted with a strong chemical etching component; but that $\mathrm{Cl}$ - and $\mathrm{Br}$ based etching require ion bombardment. The behavior of $\mathrm{Si}_{1}-x \mathrm{Ge}_{x}$ alloys, $x<0.20$, is therefore in this respect the same as that of $\mathrm{Si}^{7}{ }^{7} \mathrm{~A}$ more detailed discussion of the processing parameters and etch profile results will be presented elsewhere. ${ }^{15}$ The topic which we wish to discuss in the remainder of this letter are the mechanistic implications of the observed increase of the SiGe etch rate with $\mathrm{Ge}$ content.

The most straightforward explanation of the increase of the SiGe etch rate with Ge is that it is due to the greater gasification rate of Ge atoms and that the removal of Si and Ge atoms by the etchant atoms from the SiGe surface is independent and occurs at rates measured for the pure elements for the same plasma conditions. The curves labeled "a" in Figs. 2(a)-2(c) are the predictions of this SiGe etehing model for $\mathrm{CF}_{4}, \mathrm{CF}_{2} \mathrm{Cl}_{2}$, and $\mathrm{HBr} \mathrm{RIE}$, respectively. The model results are shown together with experimental data obtained for $\mathrm{CF}_{4}, \mathrm{SF}_{6}, \mathrm{CF}_{2} \mathrm{Cl}_{2}$, and $\mathrm{HBr}$ RIE. Figures 2(a)-2(c) demonstrate that this simple 


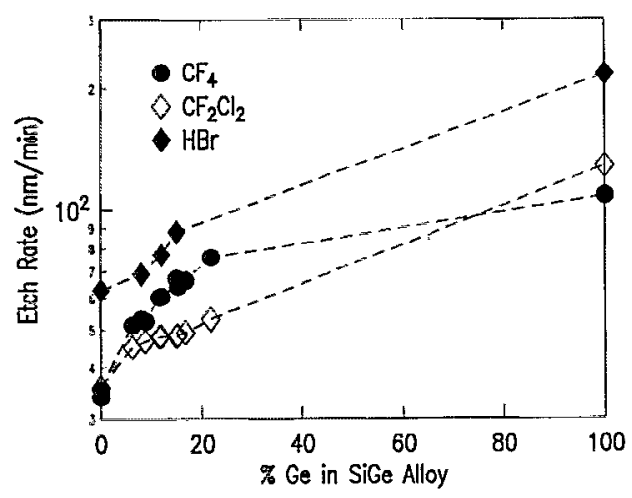

FIG. 1. Reactive ion etch rates of epitaxial SiGe films in $\mathrm{CF}_{4}, \mathrm{CF}_{2} \mathrm{Cl}_{2}$, and $\mathrm{HBr}$ plasmas as a function of the alloy composition.

model significantly underestimates the dependence of the etch rate of $\mathrm{SiGe}$ alloys on the Ge content for all etchants. This is the case even if one assumes that the removal rate of Ge atoms is infinitely fast [curves "b" in Figs. 2(a)$2(\mathrm{c})]$. One may atfempt to improve model "a" by taking into account the following effect: Due to the presence of $\mathrm{Ge}$

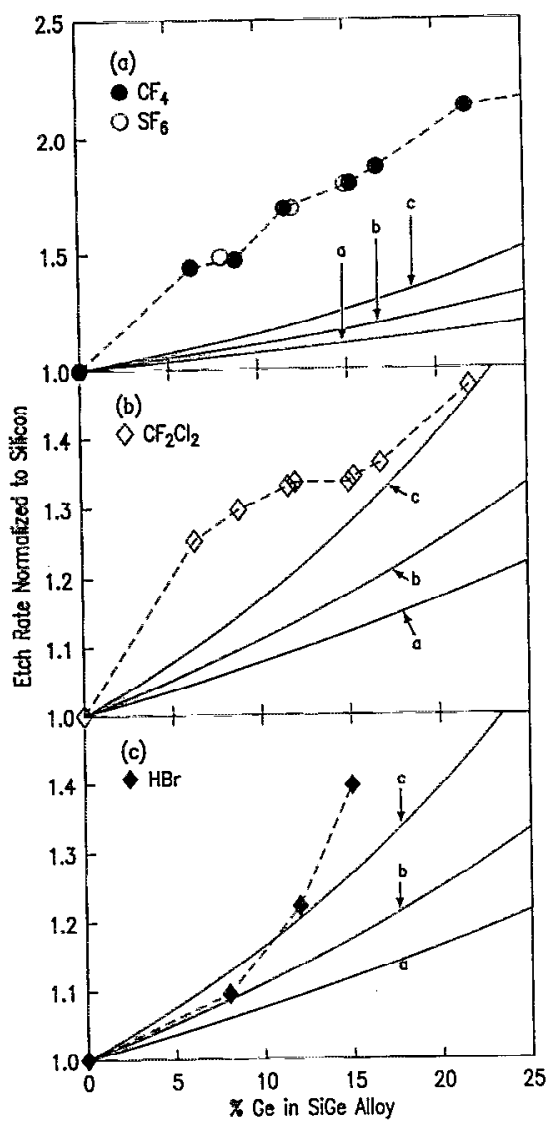

FIG. 2. (a) Comparison of the dependence of the $\mathrm{SiGe} / \mathrm{Si}$ etch rate ratio in $\mathrm{CF}_{4}$ on the $\mathrm{Ge}$ content of $\mathrm{SiGe}$ alloys with the predictions of etching models. In model " $a$ " the removal of $\mathrm{Si}$ and Ge atoms of the SiGe alloy is independent and occurs at experimentally measured etch rates of the elements. Model " $b$ " is the same as " $a$ " but the Ge etch rate is assumed to be infinite. Modcl " $c$ " is the same as model "a", but an equal number of Si atoms are gasified at a rate equal to that of the Ge atoms. (b) Same as (a) for $\mathrm{CF}_{2} \mathrm{Cl}_{2}$ RIE. (c) Same as (a) for $\mathrm{HBr} \mathrm{RIE}$ atoms in the SiGe alloy a certain number of $\mathrm{Si}-\mathrm{Si}$ bonds are replaced by $\mathrm{Si}-\mathrm{Ge}$ bonds which are characterized by a smaller bond strength $(3.12 \mathrm{eV}$ is the bond strength of the diatomic molecule $\left.{ }^{16}\right)$ than $\mathrm{Si}-\mathrm{Si}$ bonds $(3.25 \mathrm{eV}$ diatomic $\left.^{16}\right)$. The lower bond strength will increase the ease with which halogen atoms can attack this bond and, when the $\mathrm{SiGe}$ bond is broken, equal numbers of $\mathrm{Ge}$-halogen and $\mathrm{Si}$-halogen bonds are formed. This effect was taken into account in curves "c" of Figs. 2(a)-2(c) where it was assumed that the rate of volatilization of the Ge atoms and an equal number of $\mathrm{Si}$ atoms in the $\mathrm{SiGe}$ alloy proceeds at the rate measured for Ge atoms in single-crystal Ge. Figure 2(a) shows that for fluorine-based RIE the possible etch rate enhancement with increasing Ge content given by this model is smaller than the experimental data. Also for $\mathrm{Cl}$ - and Br-based RIE no good agreement with experiment is found [see Figs. 2(b) and 2(c)]. We need to conclude from these comparisons that the effect of the presence of Ge in the SiGe alloy on etch rate is more profound than just replacing a certain number of $\mathrm{Si}$ atoms with $\mathrm{Ge}$ atoms having different etching properties. The presence of $\mathrm{Ge}$ in the $\mathrm{SiGe}$ alloy increases the rate of volatilization of $\mathrm{Si}$ atoms as compared to rates measured for single-crystal Si. When discussing Fig. 1 we noted that the SiGe etch rate increased most strongly with Ge content for the F-based plasmas. This observation is now understandable since F-based etching of Si is characterized by a high spontaneous, chemical etch rate, and an increase in the $\mathrm{Si}$ atom reactivity due to the presence of Ge atoms in the crystal lattice will have a large effect on the etch rate. On the other hand, etching of $\mathrm{Si}$ and SiGe using chlorine and bromineplasmas relies on ion bombardment and a change in the reactivity of the substrate will have a smaller effect on the etch rate.

A small Ge concentration in the SiGe bulk could affect the volatilization of all substrate atoms if it would be enriched at the surface. At the surface it could facilitate by an (unknown) catalytic mechanism gasification of $\mathrm{Si}$ atoms but remain itself concentrated on the surface (all stoichiometrically complete germanium-halogen products are less volatile than the corresponding silicon-halogen products $^{16}$ ). For instance, increased growth rates of SiGe alloys due to germane addition have been explained by the prescnce of Ge on the SiGe surface which is thought to catalyze silicon growth by causing increased hydrogen desorption from $\mathrm{Ge}$ sites and enabling increased adsorption of film precursors on the growth surface. ${ }^{5,12}$ We could postulate a similar mechanism for dry etching where Ge atoms at the surface could increase halogen adsorption and increase Sihalogen product formation and desorption rates. A necessary but not sufficient condition for this kind of mechanism is Ge enrichment of the SiGe surface during etching. In Fig. 3 the $\mathrm{Ge} / \mathrm{Si}$ surface element ratio of $\mathrm{SiGe}$ alloys after RIE obtained from the intensities of the Ge $3 p$ and $\mathrm{Si} 2 p$ photoemission peaks is displayed as a function of the bulk $\mathrm{Ge} / \mathrm{Si}$ ratio (measured by Rutherford backscattering spectrometry). The $\mathrm{Ge} / \mathrm{Si}$ ratios after $\mathrm{CF}_{4} \mathrm{RIE}$ are greater than the bulk Ge/Si values, i.e., the etched alloy surface is Ge rich. On the other hand, after $\mathrm{CF}_{2} \mathrm{Cl}_{2}$ and $\mathrm{HBr} \mathrm{RIE}$ the 


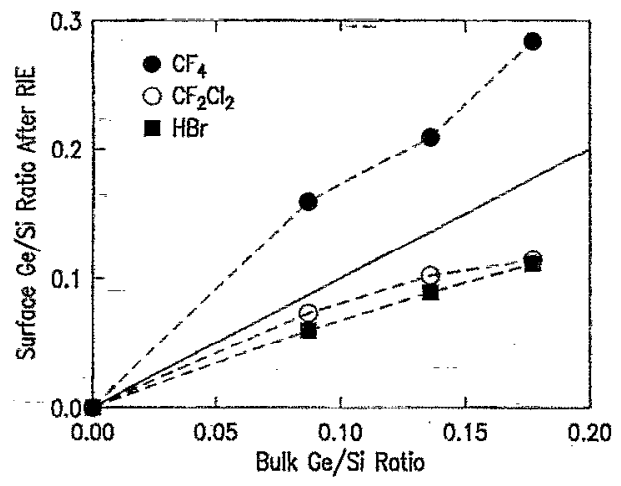

FIG. 3. Ge/Si element ratio in the surface region of SiGe alloys after RIE as determined by XPS vs the bulk Ge/Si ratio which was obtained by Rutherford backscattering spectrometry.

surface $\mathrm{Ge} / \mathrm{Si}$ ratio is less than the bulk Ge/Si ratio, showing that the surface region is Si rich. The Ge enrichment of the SiGe surface after $\mathrm{CF}_{4}$ and $\mathrm{SF}_{6} \mathrm{RIE}$ is at least qualitatively consistent with a role of $\mathrm{Ge}$ in the elementary steps of the etching reaction. However, for $\mathrm{CF}_{2} \mathrm{Cl}_{2}$ and $\mathrm{HBr} \mathrm{RIE}$ the $\mathrm{SiGe}$ surface is $\mathrm{Si}$ rich and the $\mathrm{SiGe}$ etch rates are nevertheless enhanced over the independent species volatilization model. This indicates that other effects must be important as well in enhancing the SiGe etch rates, e.g., differences in electronic structure and strain between the SiGe alloys and a Si crystal may enhance the SiGe etch rates:

Changes in the electronic properties of the SiGe substrate could enhance the SiGe etch rate by increasing the availability of electrons at the substrate surface which is the basis of the "doping effect" in $\mathrm{Si}^{8,17-19}$ For the SiGe films with the highest Ge concentration studied in this work the minimum band gap is $\approx 1 \mathrm{eV}$ as compared to 1.17 $\mathrm{eV}$ for unstrained $\mathrm{Si}^{1}{ }^{1}$ (The band alignment and band offsets of SiGe with the Si substrate depend additionally on the presence of strain in the Si substrate. ${ }^{1}$ ) These changes of the electronic properties of the SiGe alloy with Ge content make electron transfer from the semiconductor to chemisorbed halogens easier and are qualitatively consistent with the observed etch rate increase. The magnitude of the etch rate increase with impurity concentration seen here is smaller than etch rate effects seen for the electronic dopants, e.g., the etch rate increase of a SiGe alloy containing $\simeq 20 \%$ of Ge over that of Si is only a factor of 2 for $\mathrm{F}$ and less than that in the case of $\mathrm{Br}$. The smaller changes in the etch rates are qualitatively consistent with the more subtle changes of the electronic properties of SiGe alloys with increasing Ge content (as compared to changes introduced by the addition of group III and group VI dopants to $\mathrm{Si}$ ).

$\mathrm{Si}$ and $\mathrm{Ge}$ in the pseudomorphic SiGe alloy on a $\mathrm{Si}$ substrate are highly strained which could increase the rate of formation of a volatile, strain-reducing phase. We compared the etch rates of strained SiGe deposited onto $\mathrm{Si}(100)$ with partially relaxed material (obtained by annealing for $30 \mathrm{~min}$ at $950^{\circ} \mathrm{C}$ which introduced dislocations at a density of $\simeq 2 \times 10^{8} \mathrm{~cm}^{-2}$ ). Within the experimental accuracy the etch rates of the two materials were the same. This result should indicate that strain effects alone do not play a dominant role.

In summary, we have studied RIE of epitaxial, strained $\mathrm{Si}_{1-x} \mathrm{Ge}_{x}$ alloys, $x \leqslant 0.20$, in fluorine-, chlorine-, and bromine-based plasmas. The etch rates of epitaxial SiGe films increase with Ge concentration for all gases examined in this work. The etch rate increase is not accounted for by the greater rate of gasification of Ge atoms alone but the presence of Ge atoms in the SiGe alloy increase the rate of $\mathrm{Si}$ etch product formation. Germanium surface enrichment for F-based RIE and changes in the electronic properties of the SiGe alloy with Ge content which increase the availability of electrons at the substrate surface are important in explaining the increased etch rates. On the other hand, strained and partially relaxed $\mathrm{SiGe}$ have the same etch rates. In future work the question why for F-based RIE the SiGe surface is Ge-rich while for $\mathrm{Cl}$ - and $\mathrm{Br}$-based RIE it is $\mathrm{Si}$ rich needs to be addressed which should also improve our understanding of the etching of these materials.

We thank K. Chan for depositing low-temperature oxide films on the SiGe alloys, M. Smyth for lithographic support, and T. Ross for the SEM micrographs. We are grateful to S. R. Stiffler for the characterization of the strained and relaxed SiGe films. Y. Z. would like to thank Protessor J. W. Corbett, SUNY at Albany, för his support.

${ }^{1}$ R. People, IEEE J. Quantum Electronics QE-22, 1696 (1986).

${ }^{2}$ G. L. Patton, J. H. Comfort, B. S. Meyerson, E. F. Crabbe, G. I. Scilla, E. de Fresart, J. M. Stork, J. Y. Sun, D. L. Harame, and J. N. Burghartz, IEEE Electron Device Lett. 11, 171 (1990).

${ }^{3}$ J. F. Gibbons, C. M. Gronet, and K. E. Williams, Appl. Phys. Lett. 47, $721(1985)$.

${ }^{4}$ B. S. Meyerson, Appl. Phys. Lett. 48, 797 (1986).

P. M. Garone, J. C. Sturm, P. V. Schwartz, S. A. Schwarz, and B. J. Wilkens, Appl. Phys. Lett. 56, 1275 (1990).

"G. S. Oehrlein, T. D. Bestwick, P. L. Jones, and J. W. Corbett, Appl. Phys, Lett. 56, 1436 (1990).

${ }^{7} \mathrm{~J}$. W. Coburn, Plasma Etching and Reactive Ion Etching (American Vacuum Society, New York, 1982 1.

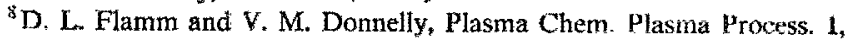
$317(1981)$.

${ }^{7}$ D. Chin, S. H. Dhong, and G. J. Long, J. Flectrochem. Soc. 132, 1705 (1985).

${ }^{10} \mathrm{M}$. Nakamura, K. Iizuka, and H. Yano, in Proceedings Tenth Symposium Dry Process, edited by Jun-ichi Nishizawa (Institute of Electronic's Engineers, Tokyo, Japan, 1988), p. 58:

${ }^{11}$ T. D. Bestwick and G. S. Oehrlein, J. Vac: Sci. Technol. A 8, 1696 (1990).

${ }^{12}$ B. S. Meyerson, K. J. Uram, and F. K. LeGoues, Appl. Phys. Lett. 53, 2555 (1988).

${ }^{13}$ G. S. Oehrlein and HL. L. Williams, J. Appl. Phys. 62, 662 (1987).

${ }^{14}$ G. S. Oehrlein, S. W. Robey, and J. L. Lindström, Appl. Phys. Lett. 52, $1170(1988)$.

${ }^{15} \mathrm{G}$. S. Oehrlein, G. M. Kroesen, E. de Frésart, Y. Zhang, and T. D. Bestwick, J. Vac. Sci. Technol. A 9,768 (1991).

${ }^{16}$ Handbook of Chemistry and Physics, 57th Edition, edited by $\mathrm{R}$ : $\mathrm{C}$. Weast (CRC, Cleveland, $\mathrm{OH}, 1976$ ).

${ }^{17}$ G. C. Schwartz and P. M. Schaible, J. Electrochem. Suc. 130, 1898 (1983).

${ }^{18}$ H. F. Winters and D. Haarer, Phys. Rev. B 36, 6613 (1987).

${ }^{19}$ E. A. Ogryzlo, D. E. Ibbotson, D. L. Flamm, and J. A. Mucha, I. Appl. Phys. 67, 3115 (1990). 